PUPIL: International Journal of Teaching, Education and Learning

ISSN 2457-0648

Fu, Lanping, 2022

Volume 5 Issue 3, pp. 162-182

Received: 14th September 2021

Revised: 13 th January 2022, 31 ${ }^{\text {st }}$ January 2022

Accepted: 02 ${ }^{\text {nd }}$ February 2022

Date of Publication: 04th February 2022

DOI- https://doi.org/10.20319/pijtel.2022.53.162182

This paper can be cited as: Lanping, F. (2022). The Effect of Technology-Enhanced Learning Approach on EFL Learners' Listening Skill. PUPIL: International Journal of Teaching, Education and Learning, 5 (3), 162-182. This work is licensed under the Creative Commons Attribution-NonCommercial 4.0 International License. To view a copy of this license, visit http://creativecommons.org/licenses/by-nc/4.0/ or send a letter to Creative Commons, PO Box 1866, Mountain View, CA 94042, USA.

\title{
THE EFFECT OF TECHNOLOGY-ENHANCED LEARNING APPROACH ON EFL LEARNERS' LISTENING SKILL
}

\section{Fu Lanping}

Master student at Department of English \& Applied Linguistics, Brother Andrew Gonzales College of Education, De La Salle University, Manila, Philippines

lanping_fu@dlsu.edu.ph

\begin{abstract}
Listening skills, as one of the four macro skills in language teaching, is regarded as the most difficult one by some educators. This meta-analysis, computing the data from 20 previous studies, aims at studying the effect of a technology-enhanced learning approach on English learners' listening comprehension. It also studied the difference between the effect of different treatment types and treatment length. Data shows that the technology-enhanced learning approach help learners improve more than the traditional learning approach, CALL works better than MALL and long-term treatment have greater effect than short term one, which suggests the application
\end{abstract}


PUPIL: International Journal of Teaching, Education and Learning

ISSN 2457-0648

of suitable learning aid as well as a longer application.

Keywords:

CALL, MALL, EFL, Listening Comprehension, Listening Skill

\section{Introduction}

We all know that listening is one of the four macro skills in language teaching and learning and it is regarded as the first of the four skills. But what actually listening is? What is the definition? Generally speaking, regarding the procedure of listening, we could consider that listening is receiving language through our ears, identifying the sounds of speech and processing them into words and sentences and then understanding the meaning of the speech. Just like Brownell (2002) said, listening is the process of receiving, constructing meaning from and responding to spoken and/or non-verbal messages. During such a procedure, people use their ears to capture individual sounds and we use the brain to convert them into meaningful information. There are different ideas on the definition of listening. Byrnes (1984) stated that listening comprehension is a highly complex problem-solving activity and it can be broken down into a set of distinct sub-skills. Some take it as an interactional and active process, during this process the listener would receive the speech and try to attach it with meanings. The listener tries to understand the intended meaning of the speaker(s) so that he/she could respond effectively to oral communication.

According to Helgesen (2003), listening is a process that is an active, purposeful process during which, people make sense of what they hear. And listening skill is important for everyone, it is used nearly twice as much as reading and writing so we should pay more attention to listening during language learning. A meta-analysis, at the first glance, could be complex and intimidating for its calculating of the mean and variance of a set of numbers and it is statistical (Oswald, 2010). This meta-analysis would focus on the learning approach to help improve EFL students' listening skills. 


\section{Background}

Listening comprehension could be affected by many factors, this chapter would give an introduction to the factors referring to the proposal of Nunan (1988). The new approach of language teaching is also introduced.

\subsection{Factors Affecting Listening Comprehension}

Nunan (1988) proposed that there are four factors influencing a learner's success in listening comprehension, say the listener, the speaker, the content and visual support.

The first factor, the listener probably is the most important central one in the listening process. The listener's pronunciation, grammar knowledge, his knowledge of how sounds would be reduced or merged, his vocabulary size, his concentration would all affect his understanding and thus affect the listening process. Moreover, if he is interested in the topic of the dialogues or the spoken text, then he would be more likely to learn about it and he would have deeper comprehension on the said content. His background knowledge on the topic would have influence on the comprehension on the listening topic.

The speaker also has influence on the listener' success. His pronunciation, his accent and dialect, his grammar, his rate of delivery would affect the comprehension process. For example, if the speaker speaks too fast, the listener would be confused by his mumble like utterance. So, the speaker would better adjust his speaking speed according to the condition or language level of the listener. As for the accent and dialect aspect, a speaker with standard American English accent would be more understandable. When it comes to the teaching scenario, the teacher need choose the listening material that suits the students' level.

Another influencing factor is the content of the spoken sentences. It is related with the above-mentioned listener's background knowledge and his interest on the topic. Content is easier to understand when it is familiar to the listener or the listener has background knowledge on it, and in that case, the meaning is easier to grasp.

The last factor that has influence is visual support which may be pictures, diagrams, facial expressions, body language and video. Listening would be much easier in a condition that you 
could see the speaker's body language. A lot of things and details would get lost in speech, but if you see, such as an ironic smirk, you would understand and catch the unsaid meaning.

\subsection{New Technology and Listening Teaching}

The development of technologies has changed our life in various perspective. It would have influence on the education landscape undoubtedly. Under this condition, the teaching of language have changed from the traditional "chalk-and-talk" method to more collaborative student-centered learning methods.

Computer assisted language learning (CALL) is a technology-enhanced language learning approach which would make in-depth use of computer and computer-based resources such as the Internet. It could present, reinforce and assess the target materials. CALL would support the faceto-face language instruction but it would not replace it.

Like Pierce (2013) stated, technology development, with increasing scope of available content demand us to reshape traditional learning and teaching models. Traditional approaches are intended to be reconstructed to innovative model that would make use of online activities and other free educational resources. Some scholars have indicated that flipped classroom model would fit the requirements. Flipped classroom model, according to Bates \& Galloway (2013) is inverted and it is also reverse and backwards. In traditional classroom type, target learning goals are taught by teachers and teachers would give assignments or homework to students for their accomplishment outside the classroom. However, for the flipped learning classroom, the input part is delegated off-site within the flipped classroom framework while classroom activities are taken as a follow up. Before the classroom, students would study the learning materials prior ahead, and during class time they would do application, inquiries and assessments. Thus, this model would allow the students focus more on the application of the target knowledge and thus it would help to avoid learning on the surface. Rudneva, Valeeva, Zakirova, Guslyakova \& Pavlova (2020) made a research on the influence of flipped classroom approach. They studied the performance of 35 Russian students and the students are requested to complete listening assignments based on YouTube videos weekly and followed up by on-site discussions. Research result of their pre- and 
post-test score was analyzed by paired samples t-test and thus the differences between the mean scores of the experimental group and observation group could be evaluated. The post-test revealed an obvious improvement regarding students' listening comprehension skills in experimental group. And according to the result, flipped classroom model is of great benefit to improve learners' listening comprehension skill. The research of Baharum et al. (2020) also confirmed the effectiveness of the flipped classroom. It stated that flipped learning method could increase learning effectiveness under the assistance by M-Learning application.

According to Hardy \& Kim (2000), new technology supplement such as computer and mobile device have its advantages in teaching listening of a language. In developing content materials, they demonstrated that activities by computers are superior to the ones by textbook in supporting listening comprehension skills by ensuring interactivity. They also indicated that interactivity could be achieved in computer-assisted study by a) providing a variety of formative immediate feedback which guides students through the language; b) giving students the opportunity to react after feedback and self-correcting the messages; c) supplying students options within an activity, such as HELP panels, hints, glossaries, to name a few; and d) using multimedia, for example sound, video, graphics, and animations. Regarding on this issue, this meta-analysis aims at presenting a relatively comprehensive and through review on the effects of teaching listening in English under technology enhanced learning approach with the assistance of device like computer, mobile device and multimedia equipment.

\section{Variable \& Research Questions}

The independent variables evaluated here in this research is technology enhanced learning approach; the moderator variables are the type of treatment CALL (Computer Assisted Language Learning) or MALL (Mobile Assisted Language Learning), and length of treatment. Other factors such as the research settings and students' age were also coded. The dependent variable is the effect size derived from the included 20 previous studies. The importance of the independent 
variables is already self-evidenced, the rational for investigating the moderator variables needs to be further explained and major moderators would be discussed below.

\subsection{Research Setting}

Research setting here in this meta-analysis could be divided into foreign language (FL) and second language (SL). Foreign language setting where the learner studies a language that is not the primary language of his/her linguistic community; which second language setting is where the learner's target language is the primary language of the linguistic community. Since the dynamics of such two settings are different, the technology enhanced approach may be different accordingly. The included studies of this meta-analysis are all under EFL setting.

\subsection{Length of treatment}

Treatment duration of the included studies varies. The impact of this variable should usually be evaluated with other variables like the learner difference, it is interesting to examine whether treatment length alone has any influence on the effects of technology enhanced learning approach (L I \& Ellis, 2012).

\subsection{Learners' Age}

The learners in the included primary studies have varied age range. They could be young primary school students or elder university school students, but no study examined age as an independent variable.

As we can see form above, the methodology or learner characteristics could affect the effectiveness of technology enhanced learning approach potentially. This meta-analysis aims to answer the following questions:

1. What is the overall effect of technology enhanced learning/teaching approach in the improvement of English listening skill?

2. Do different types of technology enhanced approach impact English listening skill learning differently?

3. Does the length of treatment have influence on the effect? 


\section{Method}

This Meta introduction computed data from 20 previous studies. The identification of previous studies, and the coding of these studies are done in this chapter to build the foundation for data analysis.

\subsection{Identify Primary Studies}

To locate related primary studies, some methods were applied. Firstly, the researcher used electronic database in the fields of applied linguistics and education ERIC and Jstor to search for related studies. The keywords and combination of keywords were applied. They include, computer, technology, teaching listening, teaching English, CALL, multimedia, MALL, mobile device, listening learning, language education, teaching approach. The researcher also applied ancestry chasing, which is tracking the reference in primary research and computer search by google with above mentioned keywords were also applied.

\subsubsection{Inclusion/Exclusion Criteria}

The inclusion criteria of this meta-analysis are as follows:

a. One of the independent variables should be technology enhanced learning/teaching approach, no matter it is computer assisted language learning, or mobile assisted language learning or learning with multimedia.

b. The primary study should focus on the English listening skills of students, or on overall English language skills but with study/analysis on English listening skills. For example, some research studies the influence of CALL on students' TOEFL score but with analysis on students' listening score. Such a study could be included according to this.

c. The study should be experiential or quasi-experimental and have experimental and control groups or pre and post-test so that learning/teaching effect after treatment can be observed through comparing the gains of experimental group and gains of the control group.

d. The effect of technology enhanced learning/teaching approach could be disentangled from the effects of other factors.

e. It should utilize statistical analyses to investigate mean differences so that there would be 
necessary data to compute the effect size and do deeper data analysis.

f. It should be published in English.

\subsubsection{Exclusion Criteria of this meta-analysis is as follows:}

a. It does not have enough data reported for the computation of effect size.

b. The research design makes it impossible to disentangle the effect of technology enhanced learning/teaching approach from other factors in the treatment.

c. It is not about English language learning.

d. It was published before the year of 2000 .

\subsection{Coding}

Since the coding of a meta-analysis is of vital importance and complicated, the coding of this meta-analysis was done carefully with modification and revisions. Firstly, titles of the searched studies were screened for clearly ineligible publication. Then the keywords and abstracts were coded for eligibility. After that, the remaining studies were retrieved and coded at the full text level, with focus on the methodology and data analysis parts.

\subsubsection{Treatment instrument}

There are many treatment types used in the included studies to improve students' listening comprehension ability in English. Some applied CALL (Computer Assisted Language Learning), MALL (Mobile Assisted Language Learning) while others applied multimedia methods such as video, podcast and PPT. They were coded as either CALL or MALL according to the tool used.

\subsubsection{Timing of Posttest}

According to Keck, Iberri-Shea, Tracy-Ventura, and Wa-Mbaleka (2006), if posttest of a treatment in a study is less than 7 days, then it is coded as immediate posttest; if it was applied 829 days after the treatment, then it is coded as short-term delayed; if it was applied 30+ days after the treatment, it is coded as long-term delayed posttest.

\subsubsection{Measure of Proficiency}

Like Keck et al (2006) indicated, if the participants' proficiency level was evaluated according to the researcher's personal evaluation, then it is impressionistic judgment; if according 
to the enrollment in a language class or program, then it is institutional status; if it used a placement test or a test created by the researcher, then it is in-house assessment; if based on participants' performance on an already established test such as TOEFL, then it is standard test.

\subsubsection{Length of Treatment}

In the meta-analysis of $\mathrm{Li}$ (2010), he coded the length of treatment as short treatment if it was less than $50 \mathrm{~min}$, medium if between 60-120 min, and long if over medium. Since the cutoff of the treatment length could be arbitrary, considering the actual length of overall included studies, this meta-analysis would have a different coding category. If the treatment was one month or less, it was coded as short term; if more than one month but below two months, it was coded as medium term; if more than two months, then it was long term.

\subsubsection{Learner's Age}

In Li (2010), for studies that reported participants' average age, the original mean age was recorded; for studies that reported participants' enrollment at school, such as "university students," "freshmen," and so on, their age was estimated (e.g., 12 for "sixth graders" and 18 for "freshmen"); for studies that reported a narrow range such as "18-20," the median (19) was taken as the average age; for studies that did not provide any related information or provided a wide range such as "18-55," they were coded as such and were not included when the age effect was investigated. This study would apply the same age coding method.

Table 1: coding result of included studies

\begin{tabular}{|c|c|c|c|c|c|c|}
\hline Included Study & $\begin{array}{l}\text { Treatment } \\
\text { Instrument }\end{array}$ & Age & $\begin{array}{l}\text { ESL/ } \\
\text { EFL }\end{array}$ & $\begin{array}{l}\text { Length of } \\
\text { Treatment }\end{array}$ & Timing of Post-test & $\begin{array}{l}\text { Measure of } \\
\text { Proficiency }\end{array}$ \\
\hline $\begin{array}{c}\text { Khoshsima \& } \\
\text { Mozakka (2017) }\end{array}$ & CALL & N/A & EFL & medium term & immediate & standard \\
\hline Ampa (2015) & CALL & 20 & EFL & N/A & immediate & $\begin{array}{l}\text { in-house } \\
\text { assessment }\end{array}$ \\
\hline Ardiansyah (2018) & CALL & 19 & EFL & long term & immediate & $\begin{array}{l}\text { in-house } \\
\text { assessment }\end{array}$ \\
\hline
\end{tabular}


Deng (2018) CALL 19 EFL N/A immediate $\begin{gathered}\text { in-house } \\ \text { assessment }\end{gathered}$

Faramarzi (2019) CALL N/A EFL long term immediate in-house

Han \& Rensburg (2014)

CALL 19 EFL medium term immediate assessment

Heidar \& Akbar (2015)

CALL N/A EFL short term immediate in-house

Hsu, Hwang \&

Chan (2014)

CALL 20 EFL N/A immediate

assessment

Ikonta \& Ugonna

(2015)

$\begin{array}{llll}\text { CALL } & 19 & \text { ESL N/A }\end{array}$

in-house

assessment

in-house

assessment

Khoii \& Aghabeig

CALL 15 EFL medium term

immediate

standard

Kilickaya (2007)

CALL 19 EFL medium term immediate

standard

Lan (2015)

CALL 19 EFL long term

immediate

in-house

Qasim \& Fadda

CALL 21 EFL medium term immediate

assessment

Rahimi \&

Soleymani (2015)

MALL 18 EFL long term immediate

in-house

Sarani, Behtash, \& Arani (2014)

CALL N/A EFL long term immediate

assessment

Sehati (201\&)

CALL N/A

EFL medium term immediate

standard

Sejdiu (2017)

MALL 8 EFL long term

immediate

Vahdat \&

Eidipour (2016)

CALL 13 EFL medium term

immediate

in-house

assessment

Yamada,

Kitamura,

Shimada,

MALL N/A EFL short term

immediate \& long- in-house term delayed assessment Utashiro, Shigeta,

Yamaguch, 
Harison, Yamuchi,

\& Nakahra (2011)

\begin{tabular}{ccccccc}
$\begin{array}{c}\text { Ramos \& Arturo } \\
(2017)\end{array}$ & MALL & 19 & EFL & N/A & immediate & $\begin{array}{c}\text { in-house } \\
\text { assessment }\end{array}$ \\
\hline
\end{tabular}

(Source: Self)

\section{Data Analysis}

In this data analysis part, the data extracted from the identified 20 previous studies are computed. Effect size computation and moderator analysis are made to give answers to the proposed research questions.

\subsection{Effect Size Calculation}

In this meta-analysis, if a study has a control group and experimental group with pre and post-test, and the only difference between the experimental group and control is caused by the application of technology-enhanced learning method, then effect size was computed by comparing the difference of pre and post-test of experimental group and the control group.

If a study had control group and the only difference between the experimental group and control is caused by the application of technology-enhanced learning method, then effect size was computed by comparing the experimental group and the control group.

If a study had no experimental and control group but pre and post-test, and the only difference between the experimental group and control is caused by the application of technologyenhanced learning method, then effect size was computed by comparing the difference of pre and post-test.

The equation applied is:

$$
\mathrm{d}=\frac{\text { MeanDifference }}{\text { PooledSD }}
$$


While mean difference is the difference between the mean change score of the experimental and control group or between the mean score of the experimental group and control group. The Pooled SD (pooled standard deviation) was calculated as:

$$
s_{p}=\sqrt{\frac{\left(n_{e}-1\right) s_{e}{ }^{2}+\left(\mathrm{n}_{\mathrm{c}}-1\right) s_{c}{ }^{2}}{n_{e}+n_{c}-2}}
$$

While $n_{\mathrm{e}}$ is the number in experimental group, $S_{\mathrm{e}}$ is the standard deviation of the experimental group and calculated as:

$$
\mathrm{s}=\sqrt{\frac{1}{n-1} \sum_{i=1}^{n}\left(x_{i}-\bar{x}\right)^{2}}
$$

If the study only reported the $t$ value or F value, the following equation is applied:

$$
\begin{aligned}
& \mathrm{d}=\frac{t}{\sqrt{\text { HarmonicN } / \sqrt{2}}} \\
& \text { HarmonicN }=\frac{2 N_{1} N_{2}}{N_{1}+N_{2}}
\end{aligned}
$$

Or

$$
\mathrm{d}=\sqrt{\frac{F\left(N_{1}+N_{2}\right)}{N_{1} N_{2}}}
$$

$N_{1}$ And $N_{2}$ refers to the sample size of the two groups.

Effect size of the 20 included studies is shown in the following table:

Table 2: calculated effect size of included study

\begin{tabular}{cc}
\hline Included Study & $d$ \\
\hline Ampa (2015) & 0.219910521 \\
Ardiansyah (2018) & 0.195384071 \\
Deng (2018) & 0.044202962 \\
Faramarzi (2019) & 0.063578482 \\
Han \& Rensburg (2014) & 0.431694 \\
Heidar \& Akbar (2015) & 0.226437376 \\
Hsu, Hwang \& Chan (2014) & 0.042926237
\end{tabular}


Ikonta \& Ugonna (2015)

Khoii \& Aghabeig (2009)

Khoshsima \& Mozakka (2017)

Kilickaya (2007)

Lan (2015)

Qasim \& Fadda (2013)

Sejdiu (2017)

Rahimi \& Soleymani (2015)

Ramos \& Arturo (2017)

Sarani, Behtash, \& Arani (2014)

Sehati (201\&)

Vahdat \& Eidipour (2016)
0.062411116

0.185091657

0.391938711

0.195672570

0.041704384

0.215143237

0.224860719

0.205062103

0.093443994

0.488593417

0.377244072

0.154868757

0.084972249

Yamada, Kitamura, Shimada, Utashiro,

Shigeta, Yamaguch, Harison, Yamuchi, \& Nakahra (2011)

(Source: Self)

After the effect size of the effect size is calculated, the weighted effect size was calculated, and the following equations are applied to calculate:

$$
w=\frac{1}{v}
$$

Here " $v$ " is the variance of the estimate and could be calculated as:

$$
v=\frac{n_{1}+n_{2}}{n_{1^{*}} n_{2}}+\frac{d^{2}}{2\left(n_{1}+n_{2}\right)}
$$

While $\mathrm{n}_{1}$ and $\mathrm{n}_{2}$ are the sample size of the study and $d$ is the effect size. Then the weighted mean effect size is calculated as:

$$
d_{m}=\frac{\sum w d}{\sum w}
$$

By doing that, the weighted effect size was calculated, and the weighted effect size, say $d_{m}$ of 
the included study, is $\mathbf{0 . 1 4}$ (originally 0.143369361 ).

To test the statistical significance of the mean effect size, a $z$ test was conducted:

$$
z=\frac{d_{m}}{S E_{m}}
$$

Here the $d_{m}$ is the weighted effect size, and $S E_{\mathrm{m}}$ is the standard error of the mean effect size which could be calculated as:

$$
S E_{\mathrm{m}}=\sqrt{\frac{1}{\sum w}}
$$

And $w$ is the weight of each study.

Then $z$ value of the included studies is $\mathbf{2 . 7 8}$ (originally 2.781623578 ), which is bigger than the critical value 2.58 at $\alpha=0.05$. That means the mean effect size is statistically significant. To test the homogeneity of the effect size, a Q test was conducted:

$$
Q_{w}=\sum w\left(d-d_{m}\right)
$$

While $w$ is the weight of the effect size, $d$ being the effect size and $d_{m}$ the mean of effect

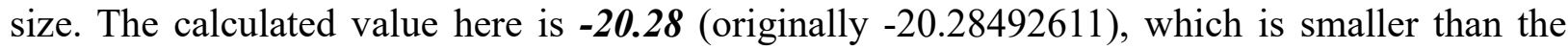
critical value $30.144(\mathrm{p}<.05)$ in chi-square table. It reveals that the effect size is homogeneous and the distribution of the effect size around the mean is caused by sampling error alone.

\subsection{Moderator Analysis}

While the Q test indicates that there is no need to proceed any moderator analysis since it revealed that the effect size of included study is homogeneous, the researcher still conducted post hoc pair-wise $Q_{\mathrm{b}}$ test for moderator analysis.

$$
Q_{b}=\sum w_{g} d_{m}{ }^{2}-\frac{\left(\sum w_{g} d_{m}\right)^{2}}{\sum w_{g}}
$$

$w_{g}$ Is the sum of the weight with in each group, $d_{m}$ is the mean effect size within each group? 
$Q_{\mathrm{b}} \quad$ Test was firstly conducted to analysis if there is main difference between the CALL group and MALL group and there $Q_{\mathrm{b}}=0.19$ (originally 0.186535371 ), see table 3, which means that this "CALL or MALL" moderator has significant impact on the variation of the group of effect size.

Similarly, $Q_{\mathrm{b}}$ test was also tested to see if the length of the treatment has significant influence on the set of effect size and there $Q_{\mathrm{b}}=0.44$ (originally 0.442986205 ). see table 4 , and which indicates that the length of the treatment has significant influence on the distribution of effect size among the groups.

Table 3: description of $Q_{\mathrm{b}}$ test

\begin{tabular}{ccc}
\hline & $w_{g}$ & $d_{m}$ \\
\hline$C A L L$ & 303.98 & 0.21 \\
$M A L L$ & 72.45 & 0.15 \\
\hline$Q_{\mathrm{b}}=0.19$ & &
\end{tabular}

(Source: Self)

Table 4: description of $Q_{\mathrm{b}}$ test

\begin{tabular}{ccc}
\hline & $w_{g}$ & $d_{m}$ \\
\hline short term & 34.39 & 0.16 \\
medium & 74.12 & 0.27 \\
long term & 161.94 & 0.20 \\
\hline
\end{tabular}

$Q_{\mathrm{b}}=0.44$

(Source: Self)

\section{Result}

The weighted effect size, $d_{m}$ is o.14 with $\mathrm{Z}$ value being 2.78 , which is higher than the critical value and which makes it statistically significant. So, generally speaking, the technology 
enhanced learning approach, with the help of computer, mobile devices or other multimedia materials works well than traditional way of learning English listening skills. Moderator analysis on the effect difference between CALL and MALL as well as that between short, medium and long-term treatment, it shows a $Q_{\mathrm{b}} \quad$ value of 0.19 and 0.44 correspondingly. According to this data, both of these two moderators have influence on the effect size. While the data is viewed together with mean effect size of each set, we could find that the CALL works better than MALL and the longer the treatment, the better the effect would be. Moreover, the length of treatment has much more significant influence on effect size than treatment type.

\section{Discussion \& Conclusion}

Seeing above results of this meta-analysis, we could get answers for the research questions already. Firstly, the overall weighted effect size of technology enhanced learning/teaching approach in the improvement of English listening skill generated by the 20 included study is 0.14 , with a $\mathrm{z}$ value higher than critical value, showing than it is statistically significant. That means the technology-enhanced learning does benefit the learning of listening skills of EFL language learners. According to Motteram (2013), digital technologies like computer program, multimedia, mobile device, are applied ideally to help teachers working with learners, and so that the learners could work independently, thus do the necessary 'language' which makes language development of the learners possible. This meta-analysis further proved it in a statistical level. In the aspect of the effect of different types of technology, (here in this meta-analysis different learning aids), the $Q_{\mathrm{b}}$ value of 0.19 is relative, which means that different learning aids do have different effect size. Seeing the effect size separately, we would find that CALL benefit learners listening skill better than MALL. A computer could provide the learners with various learning material based on individual needs and encourage learners to be more creative and original by offering them multiple options of learning methods and variety types of exercises. "Innovations such as CALL prove that computers are dominating the world of education" (Chaudhary \& Devi, 2019). MALL activities 
which are content related would tend to subscribe to a model that materials being delivered via text-messaging or a website to learners. However, very few activities of such a kind could support learner communication or collaboration (Derakhshan, 2011). And that might be the cause of its weaker effect.

Then, does the length of treatment have influence on the effect? The answer is absolutely yes, since there is a high $\quad Q_{\mathrm{b}}$ value of 0.44 , long term treatment works betters than medium term one and medium-term treatment surpass short term treatment. Moreover, the $Q_{\mathrm{b}}$ value of this moderator is much big than that of the other one (types of applied technology/learning aids) which means that the length of treatment have greater impact on the final outcome of a program.

Such result of this meta-analysis would give some implication for English teachers and language learners. Firstly, during the learning process, it's better to apply available learning aid. Suitable application of learning aids would help the learner acquire listening skills better. The types of learning aid or learning device should also be carefully selected since it would influence the outcomes and if there is an option, choose CALL but MALL in case both methods are suitable. Then, the application of new learning approach should last for a period of time so that it would benefit well. One should not expect big difference in a very short time.

\subsection{Limitation and further research}

This meta-analysis is based on 20 previous studies and because the limitation of the data included, this study only reflects above findings in a limited range and moderators. Since these are other moderators such as learners' age, gender, mother tongue or research setting (EFL or ESL) which may have influence on the final learning outcomes, future study may study these factors to enrich findings and inspire English language teaching.

\section{REFERENCES}

Ampa, A. (2015). The implementation of interactive multimedia learning materials in teaching listening skills. English Language Teaching (vol. 8, No. 12. ISSN 1916-4742 E-ISSN 
1916-4750) https://doi.org/10.5539/elt.v8n12p56

Ardiansyah, L. (2018). Using video in the teaching of listening. JIME (vol. 4. No. 1. ISSN 24429511). https://doi.org/10.36312/jime.v4i1.552

Baharum, A., Lim, Y.,Yahya, F., Hanin Nazlah, N., Mohamed Nor, A., Ismail, I., Noor, N. (2020). Mobile learning application: flipped classroom. Indonesian Journal of Electrical Engineering and Computer Science (vol. 17, No. 2). https://doi.org/10.11591/ijeecs.v17.i2.pp1084-1090

Bates, S., \& Galloway, R. (2013). “The inverted classroom in a large enrolment introductory physics course: A case study" Paper presented at the HEA STEM Conference, London, United Kingdom.

Brownell, J. (2002). Listening: Attitudes, principles, and skills (2nd Edition). Boston: Allynand Bacon.

Byrnes, H. (1984). The role of Listening Comprehension: A Theoretical Base. Foreign Language Annals, 17, 17-29. https://doi.org/10.1111/j.1944-9720.1984.tb03235.x

Chaudhary, S. \& Devi, A. (2019). Benefit of computer assisted language learning. Journal of English Language and Literature (vol.6 Issue2).

Deng, J. (2018). Computer-assisted autonomous learning of college English listening in China. Language and Communication Quarterly (volume 7, Issues 1-2, pp. 1-18).

Derakhshzadeh, A. (2011). Why CALL why not MALL: an in-depth review of Text-message vocabulary learning. Theory and Practice in Language Studies (vol. 1, No. 9, pp. 11501159). https://doi.org/10.4304/tpls.1.9.1150-1159

Faramarzi, S. (2019). The effect of vodcasting tasks on EFL listening comprehension progress in an online program. International Journal of Instruction (vol.12, No.1). https://doi.org/10.29333/iji.2019.12181a

Han, N., \& Rensburg, H. (2014). The effect of computer assisted language learning (CALL) on performance in the Test of English for International Communication (TOEIC) listening module. English Language Teaching (vol. 7, No. 2. ISSN 1916-4742 E-ISSN 1916-4750). 
https://doi.org/10.5539/elt.v7n2p30

Hardy, A., \& Kim, M. (2000). Developing content materials for computer-assisted study for enhancing listening comprehension skills in Korean. The Korean Language in America (vol. 4, Papers from the Fourth National Conference on Korean Language Education. pp. 51-62).

Helgesen, M. (2003). Teaching listening. In D. Nunan (Ed.), Practical English Language teaching. New York: McGraw-Hill.

Heidar, D., \& Akbar, A. (2015). The effect of dynamic assessment in synchronous computermediated communication on Iranian EFL learners' listening comprehension ability at upper-intermediate level. English Language Teaching (vol. 8, No. 4. ISSN 1916-4742). https://doi.org/10.5539/elt.v8n4p14

Hsu, C., Hwang, G., \& Chang, C. (2014). An automatic caption filtering and partial hiding approach to improving the English listening comprehension of EFL students. Educational Technology \& Society (17 (2), 270-283).

Ikonata, N. \& Ugonna, N. (2015). The effect of Rosetta Stone (computer-assisted language learning) software on English as second language students' proficiency in English language. African Educational Research Journal (vol. 3(1), pp. 69-79).

Keck, C., Iberri-Shea, G., Tracy-Ventura, N., \& Wa-Mbaleka, S. (2006). Investigating the empirical link between task-based interaction and acquisition. In J. Norris \& L. Ortega (Eds.), Synthesizing research on language learning and teaching (pp. 91-131). Amsterdam: Benjamins. https://doi.org/10.1075/lllt.13.08kec

Khoshsima, H., \& Mozakka, Z. (2017). The effect of computer-assisted language learning on Iranian upper-intermediate EFL learners' listening skill. Journal of Applied Linguistics and Language Research (vol. 4, pp. 81-91).

Khoii, R., \& Aghabeig, M. (2009). Computer software and the improvement of the elementary EFL students' listening comprehension. Journal of Teaching English as a Foreign Language and Literature, Islamic Azad University, North Tehran Branch (1(2), 89-101). 
Kilickaya, F. (2007). The effect of computer assisted language learning on Turkish learners' achievement on the TOEFL exam. Middle East Technical University, Ankara, Turkey.

Lan, L. (2015). The effect of computer-assisted listening instruction on Vietnamese teachers and students of English. Faculty of Education School of Curriculum and Pedagogy, The University of Auckland.

Li, S. (2010). The effectiveness of corrective feedback in SLA: a meta-analysis. Language Leaning (ISSN 0023-8333). https://doi.org/10.1111/j.1467-9922.2010.00561.x

Li, S., Shintani, N., \& Ellis, R. (2012). Doing meta-analysis in SLA: Practice, choice, and standards. Contemporary Foreign Languages Studies 384/12:1-17

Motteram, G. (2013). Innovations in Learning Technologies for English Language Teaching. British Council 2013 Brand and Design/C607 (ISBN 978-0-86355-713-2).

Nunan, D. (1998). Designing and adapting materials to encourage learner autonomy. Harlow: Longman.

Oswald, Frederick. (2010). Meta-analysis in second language research: Choices and challenges. Annual Review of Applied Linguistics (vol. 30, pp. 85-110). https://doi.org/10.1017/S0267190510000115

Pierce, R. (2013). Student performance in a flipped class module.

Qasim, N., \& Fadda, H. (2013). From Call to Mall: the effectiveness of podcast on EFL higher education students' listening comprehension. English Language Teaching (vol. 6, No. 9. ISSN 1916-4742 E-ISSN 1916-4750). https://doi.org/10.5539/elt.v6n9p30

Rahimi, M., \& Soleymani, E. (2015). The impact of mobile learning on listening anxiety and listening comprehension. English Language Teaching (vol. 8, No. 10. ISSN 1916-4742 EISSN 1916-4750). https://doi.org/10.5539/elt.v8n10p152

Ramos, L., \& Valderruten, A. (2017). Development of listening and linguistic skills through the use of a mobile application. English Language Teaching (vol. 10, No. 9. ISSN 19164742 E-ISSN 1916-4750). https://doi.org/10.5539/elt.v10n9p95

Rudneva, M., Valeeva, N., Zakirova, Y., Guslyakova, E., \& Pavlova, E. (2020). Flipped 
classroom approach to teaching ESP learning. Peoples' Friendship University of Russia. https://doi.org/10.21125/inted.2020.2004

Sarani, A., Behtash, E., \& Arani, S. (2014). The effect of video-based tasks in listening comprehension of Iranian pre-intermediate EFL learners. Gist Education and Learning Research Journal (No. 8, (January - June). pp. 29-47). https://doi.org/10.26817/16925777.112

Sehati, S. (2017). Effect of power point enhanced teaching (visual input) on Iranian intermediate EFL learners' listening comprehension ability. Journal of Educational Issues (vol. 3, No. 2 ISSN 2377-2263.). https://doi.org/10.5296/jei.v3i2.12323

Sejdiu, A. (2017). Are listening skills best enhanced through the use of multimedia technology. University of Prizren. Digital Education Review - No. 32, December 2017

Vahdat, S., \& Eidipour, M. (2016). Adopting CALL to improve listening comprehension of Iranian junior high school students. Theory and Practice in Language Studies (vol. 6, No. 8, pp. 1609-1617. ISSN 1799-2591). https://doi.org/10.17507/tpls.0608.13

Yamada, M., Kitamura, S., Shimada, N., Utashiro, T., Shigeta, K., Yamaguch, E., Harison, R., Yamuchi, Y, \& Nakahra, J. (2011). Development and evaluation of English listening study materials for business people who use mobile devices: a case study. ALICO Journal (vol. 29, No. 1. pp. 44-66). https://doi.org/10.11139/cj.29.1.44-66 